\title{
PRESENT-DAY RADIOCARBON CONTENT OF SELECT FLAVORING COMPOUNDS REVEALS VANILLIN PRODUCTION PATHWAY
}

\author{
Randy Culp $•$ G V Ravi Prasad \\ Center for Applied Isotope Studies, The University of Georgia, Athens, Georgia 30602, USA.
}

\begin{abstract}
Radiocarbon and stable isotope determination in foods, flavors, and beverages, for the authentication of source material and process of formation, is a well-established method of identity used in industry. New methods of provenance determination, using stable isotopes of oxygen and hydrogen, have added to the host of other isotopic methods used for characterizing natural or botanically derived products. The unambiguous determinant of a product's fossil fuel origin be it from petroleum, natural gas, or coal, is through the measurement of its ${ }^{14} \mathrm{C}$ content. The ${ }^{14} \mathrm{C}$ content can also be used to determine the fraction dilution of recently grown and harvested material with that derived from fossil fuel, and even confirms the vintage of agricultural products based on the well-established decrease of bomb-produced atmospheric ${ }^{14} \mathrm{C}$. This paper documents ${ }^{14} \mathrm{C}$ measurements at the University of Georgia's Center for Applied Isotope Studies accelerator mass spectrometry and stable isotope laboratories, over the last $3 \mathrm{yr}$, for 10 important flavoring compounds. By establishing an accurate and current level of ${ }^{14} \mathrm{C}$ in botanically derived products, we were able to confirm a particular source for vanilla production, the most popular consumer flavor in the marketplace. Over the years, vanilla extract has been produced less and less from vanilla beans (Vanilla planifolia), particularly those from Madagascar and the Comoros Islands, and more from other botanical precursors such as ferulic acid, clove oil, and guaiacol. We report isotopic data to support this precursor for vanilla production based on high ${ }^{14} \mathrm{C}$ levels accumulated during the tree's life, incorporated in the tree rings and their associated stable isotope abundances.
\end{abstract}

\section{INTRODUCTION}

Isotopic methods, for the determination of authenticity of food and flavoring products, are in continuous development as their applications become more complex (Dias et al. 2002; Ébongué et al. 2009). What began as a novel test for synthetic or fossil-fuel-derived components in selected flavorings, such as vinegar, cinnamon, and vanilla (Hoffman and Salb 1979, 1980; Martin et al. 1985) has now found application and importance in a myriad of products in the marketplace and in the exposure of fraudulent products (Doner et al. 1987). Early research and applications involved products like vinegar, where not only the fossil fuel source of carbon could be revealed through the use of radiocarbon measurement, but for those of natural or modern carbon origin, their specific plant source could be revealed through stable carbon isotope ratio measurement (Byrne et al. 1986; Culp et al. 1997). After years of revealing the true identity of synthetic materials, imitating natural products, by virtue of their low ${ }^{14} \mathrm{C}$ content, many natural products are now derived from manipulated modern plant derivatives to obviate the use of ${ }^{14} \mathrm{C}$ to authenticate their source. However, the need still exists for proper assessment of ${ }^{14} \mathrm{C}$ content along with stable isotope determinations in natural products.

The development of isotopic databases of natural and synthetic materials began in the late 1980s and has continued through today to assist in the authentication of natural products' sources or process of formation (Culp and Noakes 1990, 1992). With time, the number of products has grown considerably, as has the number of individual chemical compounds being scrutinized. It is important to trace isotopic trends in product source and manufacturing to discriminate between natural products and sophisticated imitations. This study reveals isotopic trends, in the last $3 \mathrm{yr}$, on a particular set of 10 compounds known to be of importance in the food and flavor industry. This data expands on previous work documenting ${ }^{14} \mathrm{C}$ activity levels in botanically derived products over more than $20 \mathrm{yr}$ (Culp and Noakes 2010). The ${ }^{14} \mathrm{C}$ data presented herein match other reports of decreasing ${ }^{14} \mathrm{C}$ activ-

${ }^{1}$ Corresponding author. Email: rculp@ uga.edu.

(C) 2013 by the Arizona Board of Regents on behalf of the University of Arizona

Proceedings of the 21st International Radiocarbon Conference edited by A J T Jull \& C Hatté

RADIOCARBON, Vol 55, Nr 2-3, 2013, p 1819-1826 


\section{R Culp \& G V R Prasad}

ity levels over the same time period, justifying the use of an annually decreasing ${ }^{14} \mathrm{C}$ activity, or reference activity, with which to compare measured ${ }^{14} \mathrm{C}$ activities from products grown within a specific year. By doing so, one is able to accurately define the proportion of fossil-fuel-derived carbon (devoid of ${ }^{14} \mathrm{C}$ ) with that derived from botanical precursors (modern ${ }^{14} \mathrm{C}$ ). The trend-lines for these described compounds, over the last $20 \mathrm{yr}$, indicate a decrease in ${ }^{14} \mathrm{C}$ activity of $\sim 9 \%$. Therefore, without the consideration of this annual ${ }^{14} \mathrm{C}$ decrease, incorrect proportions of botanically derived materials would result. For recently grown agricultural products, vintage 2011 and 2012 , the ${ }^{14} \mathrm{C}$ activity level is at or near $104 \mathrm{pMC}$. If one was to assume no addition or dilution with fossil-fuelderived components was made to a product, a ${ }^{14} \mathrm{C}$ activity of $\sim 104 \mathrm{pMC}$ would indicate a recently grown material. Products with ${ }^{14} \mathrm{C}$ activities considerably less than $104 \mathrm{pMC}$ would unambiguously indicate the presence of fossil-fuel-derived components. In the case of higher ${ }^{14} \mathrm{C}$ activities, one can only find such examples in products where compounds labeled with high-activity ${ }^{14} \mathrm{C}$ additions have been incorporated, to fraudulently imitate natural levels of ${ }^{14} \mathrm{C}$. Another possibility is that the activity reflects the higher levels in the recent past caused by aboveground nuclear bomb testing of the late 1950s and early 1960s (Nydal and Lövseth 1983; Dai and Fan 1986). Since the cessation of aboveground nuclear bomb testing, atmospheric ${ }^{14} \mathrm{C}$ activity has decreased primarily from uptake by the oceans and biomass and dilution through fossil fuel combustion and cement manufacturing worldwide.

An example of living, higher ${ }^{14} \mathrm{C}$ activity levels, preserved from the past, can be found in large growth trees. Specifically, relatively fast-growing pines such as Douglas-fir (Pseudotsuga menziesii), whose applications stem from lumber for the construction industry to vanillin for the flavor industry (Lampman et al. 1977). Through the well-known Kraft pulping process, wood cellulose is separated from lignin, sugars, and process chemicals that can be further refined using alkali and oxidizing chemicals to separate the lignin-derived aromatic compounds, including vanillin (McNichol et al. 2000). Here, we will demonstrate the precise measurement of decreasing ${ }^{14} \mathrm{C}$ concentrations in plant-derived natural products and the identification of vanillin derived from lignin by ${ }^{14} \mathrm{C}$ and stable isotope measurements.

Although the term "natural" vanilla has been reserved for vanillin derived from vanilla beans, other non-vanilla bean sources can evade detection by the ${ }^{14} \mathrm{C}$ method since they are also from a recent botanical source. Vanillin derived from lignin, the structural component of coniferous trees, and previously a minor production pathway for vanillin, has increased in occurrence. Because lignin is from pulpwood, derived from the entire tree, the ${ }^{14} \mathrm{C}$ content is the average of the yearly growth rings over the lifespan of the tree, including bomb-produced ${ }^{14} \mathrm{C}$ still in the atmosphere.

\section{METHODS}

${ }^{14} \mathrm{C}$ content was determined by liquid scintillation counting (LSC) and accelerator mass spectrometry (AMS) at the University of Georgia's Center for Applied Isotope Studies (CAIS). LSC samples were prepared by combustion to carbon dioxide followed by benzene synthesis and directly counted as benzene in modified Packard model 1050 liquid scintillation counters after addition of the requisite scintillating cocktail. Background activity was measured, and subtracted from samples, using petrochemical benzene. NIST oxalic II reference material was employed for calibration and sealed standards were used to correct for daily fluctuations in efficiency. AMS samples were prepared by combustion to carbon dioxide and reduction to graphite after cryogenic purification. Graphite was pressed into aluminum targets as were graphite from both NIST oxalic I and II reference standards for normalization (calibration) and combusted charcoal samples for background subtraction. ${ }^{14} \mathrm{C} /$ ${ }^{13} \mathrm{C}$ ratios were measured using a NEC $0.5 \mathrm{MV}$ Pelletron accelerator mass spectrometer. 
Stable isotope ratios of carbon $\left({ }^{13} \mathrm{C} /{ }^{12} \mathrm{C}\right)$ and hydrogen $(\mathrm{D} / \mathrm{H})$ were measured using Thermo (Finnigan) 252, Delta XL-plus and Delta V-plus isotope ratio mass spectrometers. Samples and standards were combusted and purified as $\mathrm{CO}_{2}$ and water with subsequent reduction of the water to hydrogen gas. NIST and IAEA standard reference materials were used for calibration of $\mathrm{CO}_{2}$ and $\mathrm{H}_{2}$ reference gases to maintain accuracy. Replicate analyses were performed on all samples to determine precision and data reported relative to international reference materials PDB for carbon isotopes and VSMOW for hydrogen isotopes.

Ten compounds of considerable interest to the food and flavor industry were selected for isotopic testing. The samples were reported to be of natural botanical origin from reliable suppliers. Samples represented various quantities used in the industry, from relatively small quantities such as maltol to large quantities such as ethyl butyrate. From 2009 through 2011, over 1400 samples were analyzed. The number of samples received for each compound, over these $3 \mathrm{yr}$, varied from as few as 60 garlic oil samples to as many as 284 vanillin samples. The 10 compounds and their respective number of samples received over this timeframe are listed in Figure 1.

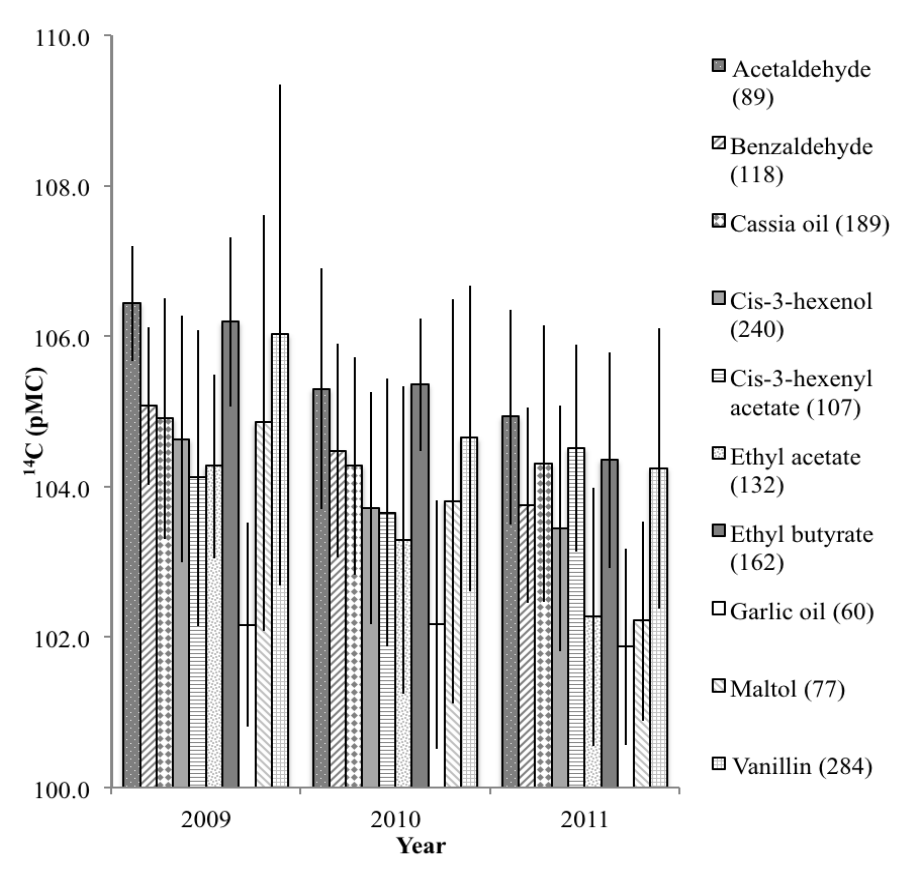

Figure 1 Yearly average ${ }^{14} \mathrm{C}$ activity of selected compounds from 2009-2011

\section{RESULTS AND DISCUSSION}

${ }^{14} \mathrm{C}$ content in natural products is one of the primary determinants of a material's authenticity. Although ${ }^{14} \mathrm{C}$ can be added to fossil-fuel-derived materials, to simulate the natural level found in plants (albeit a non-trivial task), this is rare and can be revealed through stable isotope testing. The absence of ${ }^{14} \mathrm{C}$ in a product is the unambiguous determinant of fossil fuel character in a product. With this in mind, it is critical to have an accurate point-of-reference with which to compare products from a specific growth year. Numerous studies have been conducted measuring the ${ }^{14} \mathrm{C}$ content in the atmosphere following the nuclear bomb testing of the 1950s and 1960s and subsequent decrease due to uptake by oceans and biomass after the Nuclear Test Ban Treaty. This study uses 
specific plant-derived chemical components to assess the ${ }^{14} \mathrm{C}$ content during a specific growth year. The diversity of these compounds can determine if any bias exists with regard to ${ }^{14} \mathrm{C}$ distribution during biosynthesis.

Figure 1 shows the predictable decrease of ${ }^{14} \mathrm{C}$ activity over the last $3 \mathrm{yr}$ for the 10 compounds of interest. The activity is displayed in percent modern carbon (pMC) relative to the 1950, pre-bomb ${ }^{14} \mathrm{C}$ activity level of 13.56 disintegrations per minute per gram carbon ( $\mathrm{dpm} \mathrm{g} \mathrm{C}$ ), or $100 \mathrm{pMC}$. The graph displays the variation in activity for different plant products but reveals similar levels of decrease within each plant product over the last 3 yr. Error bars representing 1 standard deviation are also shown. These indicate a high degree of variability with each year's activity level and within each plant product, greater in most cases than the annual decrease in ${ }^{14} \mathrm{C}$ activity. For each compound, the number of samples tested is shown after the compound name.

Figure 2 represents the last 3 years' data from Figure 1 appended to similarly generated data since 1987. This data, also displayed in pMC, indicates the higher ${ }^{14} \mathrm{C}$ activity levels of the past few decades. Similar to the last $3 \mathrm{yr}$, the previous $20 \mathrm{yr}$ reveal natural variability between plant products, but with similar levels of decrease in ${ }^{14} \mathrm{C}$ activity. This data allows one to model and predict the atmospheric ${ }^{14} \mathrm{C}$ activity level of the recent past as well as predict the next few years' activity with greater accuracy than from just a few data points. More important, however, is the ability to confidently express the percentage in a blend of natural and synthetic compounds by comparing the measured ${ }^{14} \mathrm{C}$ activity to the present year's activity level.

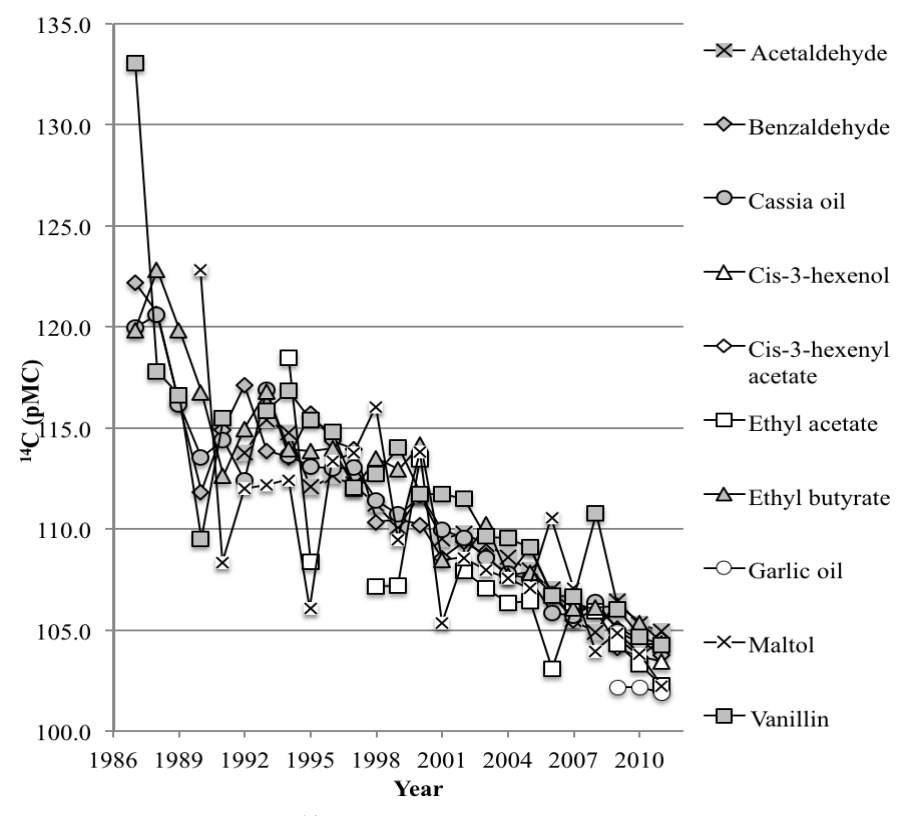

Figure 2 Yearly average ${ }^{14} \mathrm{C}$ activity of selected compounds from 1987-2011

The ${ }^{14} \mathrm{C}$ activity level determined for 1 particular compound, vanillin, revealed interesting results over the past few years that defied the normal decreasing trend in ${ }^{14} \mathrm{C}$ activity that other compounds adhered too. For a few years, primarily 2008 and 2009 , the average ${ }^{14} \mathrm{C}$ activity for vanillin samples was considerably higher than expected trend-lines would suggest. This is indicated in Figure 3 for the ${ }^{14} \mathrm{C}$ activity for vanillin samples from 1987 through 2011 . In addition to ${ }^{14} \mathrm{C}$ measurements, sta- 


\section{${ }^{14}$ C of Flavoring Compounds Reveals Vanillin Production}

ble isotope ratio data for carbon and hydrogen were generated for these samples. Figure 4 indicates the trend and variation in stable carbon and hydrogen isotope ratios from 1987 through 2011. The trend of $\mathrm{D} / \mathrm{H}$ values over this time period has slightly less variation than the ${ }^{13} \mathrm{C} /{ }^{12} \mathrm{C}$ values, which may be explained by the variable source material and their representative isotopic values for carbon and hydrogen.

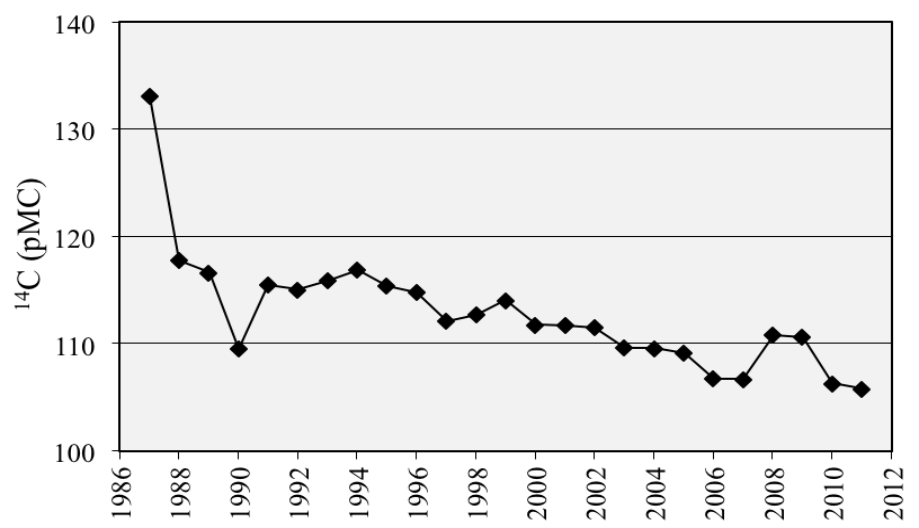

Figure 3 Yearly average ${ }^{14} \mathrm{C}$ data for vanillin samples from $1987-2011$

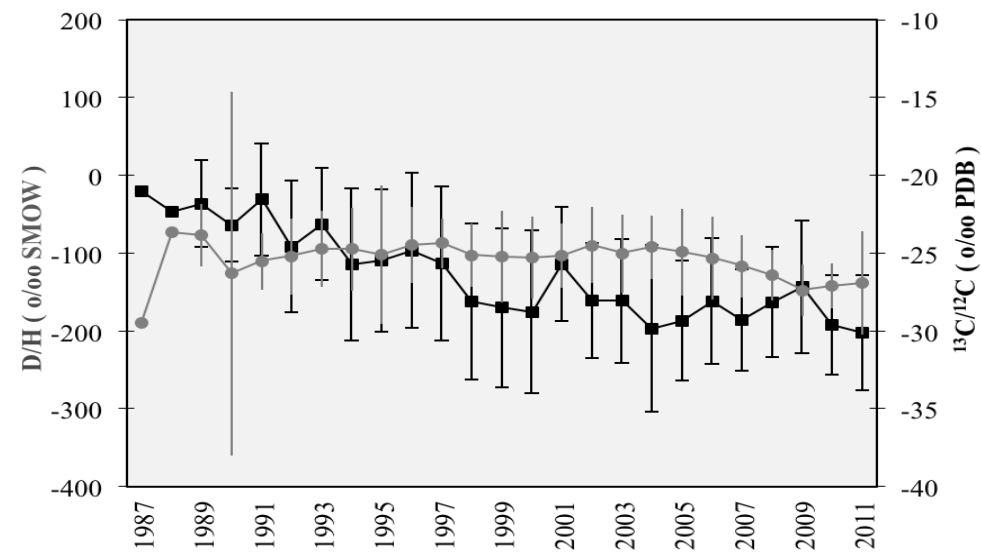

Figure 4 Yearly average stable isotope ratio data $\left(\mathrm{D} / \mathrm{H}\right.$ in gray and ${ }^{13} \mathrm{C} /{ }^{12} \mathrm{C}$ in black) for vanillin samples from 1987-2011.

Based on United States Food and Drug Administration (FDA) regulations, natural vanillin must be derived from vanilla beans. The vanilla plant or orchid, also known as Vanilla planifolia, has been traced back to southeast Mexico, where it is typically found growing within 20 degrees of the Equator and at high altitude and tropical climate. For this reason, few geographical regions are conducive to growing vanilla. Madagascar and the Comoros Islands in the Indian Ocean account for nearly $70 \%$ of vanilla production, albeit small compared to worldwide demand. To maintain supply of this high demand, alternative routes of production have been devised. Figure 5 illustrates a variety of chemical precursors to manufacture vanillin. Some precursor chemicals can be petrochemical in derivation, such as benzaldehyde and anisole, while others may be botanically derived such as eugenol and coniferyl alcohol. While ${ }^{14} \mathrm{C}$ measurement can be applied to differentiate the petrochemical from botanical precursors, the stable isotope ratio of carbon, ${ }^{13} \mathrm{C} /{ }^{12} \mathrm{C}$, can differentiate the 
botanical precursors. Natural vanillin, derived from beans, whether from Mexico, Madagascar, or the Comoros Islands, exhibit ${ }^{13} \mathrm{C} /{ }^{12} \mathrm{C}$ values near $-20 \%$. Other botanical precursors, such as eugenol, also known as clove oil, or coniferyl alcohol, from pine trees, exhibit ${ }^{13} \mathrm{C} /{ }^{12} \mathrm{C}$ values around $-32 \%$ and $-27 \%$, respectively. Coniferyl alcohol is associated with the high ${ }^{14} \mathrm{C}$ activity in vanillin samples in 2008 and 2009 and a number of samples recently tested.
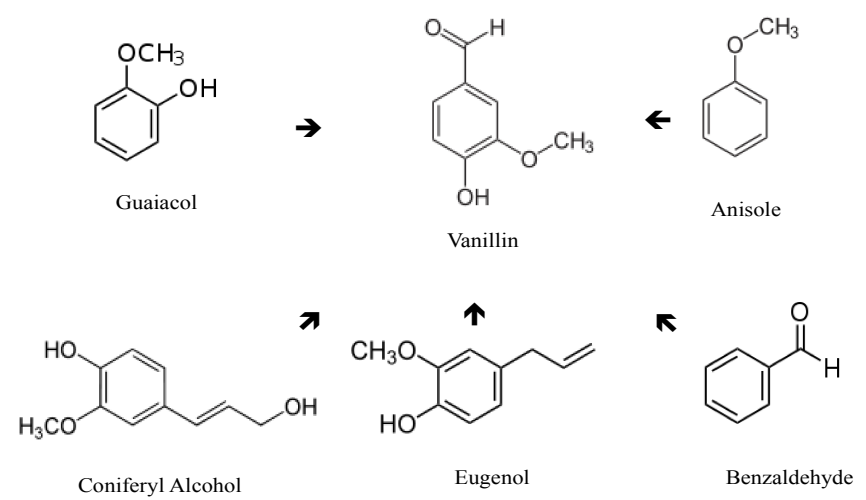

Figure 5 Chemical precursors to vanillin

Vanillin production from coniferous trees starts with the sulfite paper pulping process. A byproduct of cellulose production is a black liquid containing lignin, the structural component of woody plants. Once treated with alkali and oxidizing agents, the lignin polymer is broken down into its component aromatic phenols including vanillin. Once purified for food product use, it is structurally and chemically identical to bean-derived vanillin but with a different stable isotope ratio value and an average ${ }^{14} \mathrm{C}$ activity based on the tree's growth period. For example, lignin derived from an entire 40 -yr-old pine tree would reveal a ${ }^{14} \mathrm{C}$ activity that had an average of all 40 growth years with some consideration for faster growing seasons and annual growth mass. On average, however, pulpwood will reveal a higher ${ }^{14} \mathrm{C}$ activity when more than just the outer new-growth wood is processed. This is true since all the inner tree rings should exhibit higher ${ }^{14} \mathrm{C}$ activities for at most a 50 -yr-old tree, recalling the 1963 cessation of aboveground nuclear bomb testing.

Figures 6 and 7 show isotopic data $\left({ }^{14} \mathrm{C}\right.$ in Figure 6 and ${ }^{13} \mathrm{C} /{ }^{12} \mathrm{C}$ and $\mathrm{D} / \mathrm{H}$ in Figure 7) for 33 vanillin samples from the year 2001. They are listed by increasing ${ }^{14} \mathrm{C}$ activity and range from 0 to $\sim 125 \mathrm{pMC}$ in Figure 6. For each ${ }^{14} \mathrm{C}$ value, there are corresponding $\mathrm{D} / \mathrm{H}$ and ${ }^{13} \mathrm{C} /{ }^{12} \mathrm{C}$ data shown in Figure 7. Interestingly, the ${ }^{13} \mathrm{C} /{ }^{12} \mathrm{C}$ and $\mathrm{D} / \mathrm{H}$ values in 2001 reflect diversity in vanillin source material. In 2001, there were about 7 bean-derived vanillin products, indicated by the ${ }^{13} \mathrm{C} /{ }^{12} \mathrm{C}$ values near $-20 \%$, along with a number of petroleum-derived vanillin, accompanied by low ${ }^{14} \mathrm{C}$ activity, and a number of lignin-derived vanillin, which gave the highest ${ }^{14} \mathrm{C}$ activity.

Figures 8 and 9 show isotopic data $\left({ }^{14} \mathrm{C}\right.$ in Figure 8 and ${ }^{13} \mathrm{C} /{ }^{12} \mathrm{C}$ and $\mathrm{D} / \mathrm{H}$ in Figure 9) for 31 vanillin samples from the year 2008. Again, the samples are listed by increasing ${ }^{14} \mathrm{C}$ activity and range from 0 to only $110 \mathrm{pMC}$. Lower ${ }^{14} \mathrm{C}$ activity is expected relative to 2001 , but the ${ }^{14} \mathrm{C}$ activity should actually be closer to $105 \mathrm{pMC}$ for 2008 based on the 10 botanical compounds' ${ }^{14} \mathrm{C}$ activity. The ${ }^{13} \mathrm{C} /{ }^{12} \mathrm{C}$ and $\mathrm{D} / \mathrm{H}$ values in 2008 reflect less diversity than in 2001, with only 2 vanillin samples indicating bean derivation and the majority with ${ }^{13} \mathrm{C} /{ }^{12} \mathrm{C}$ at or around -27 or $-33 \%$. 

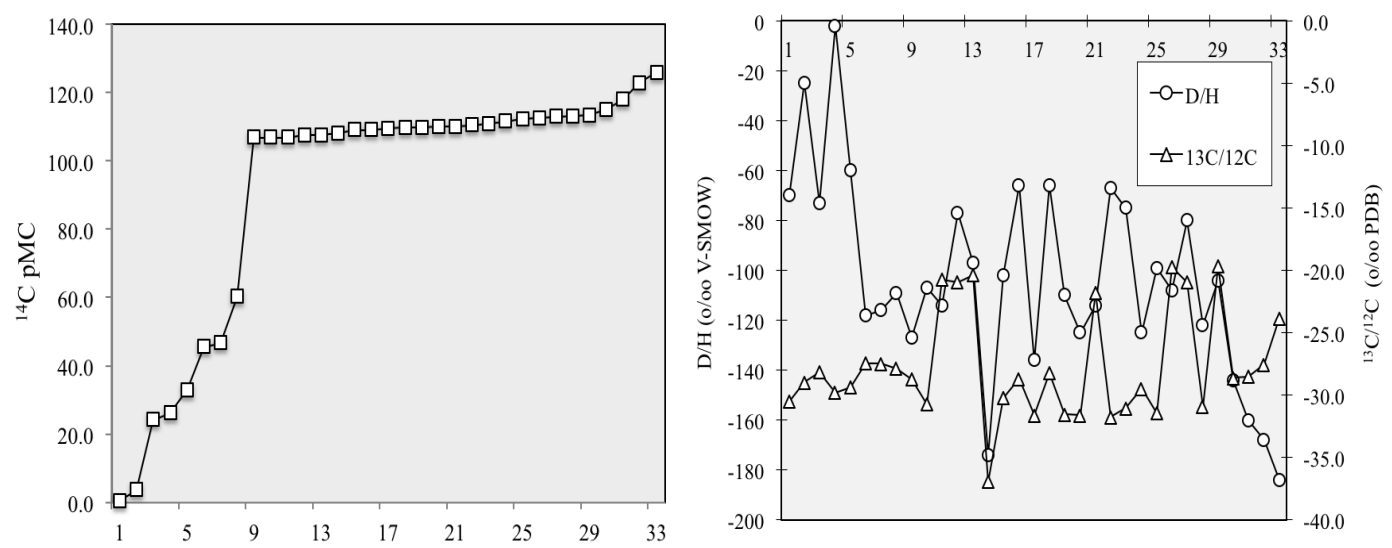

Figure 6 Isotopic data $\left({ }^{14} \mathrm{C}\right)$ for vanillin samples from 2001 Figure 7 Isotopic data $\left({ }^{13} \mathrm{C} /{ }^{12} \mathrm{C}\right.$ and $\left.\mathrm{D} / \mathrm{H}\right)$ for vanillin samples from 2001
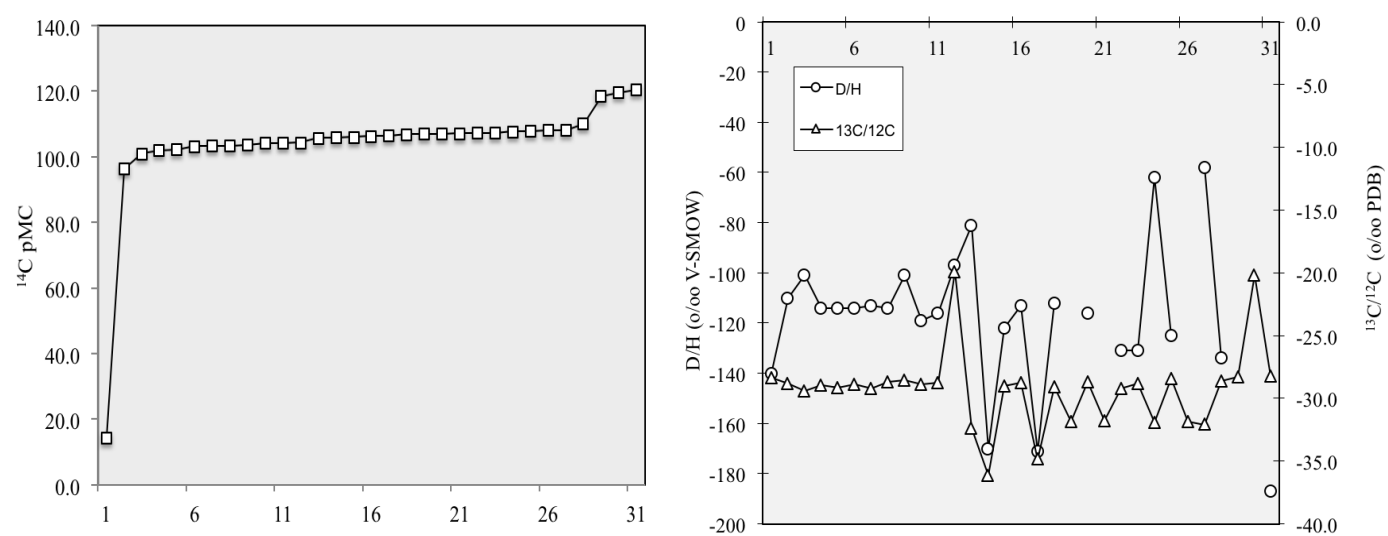

Figure 8 Isotopic data $\left({ }^{14} \mathrm{C}\right)$ for vanillin samples from 2008 Figure 9 Isotopic data $\left({ }^{13} \mathrm{C} /{ }^{12} \mathrm{C}\right.$ and $\left.\mathrm{D} / \mathrm{H}\right)$ for vanillin samples from 2008

\section{CONCLUSIONS}

This study emphasizes the accurate determination of ${ }^{14} \mathrm{C}$ activity in botanically derived products. Over the last $20 \mathrm{yr}$, isotopic data has been collected for a number of important chemical compounds used by the flavor industry. The most informative characteristic of the ${ }^{14} \mathrm{C}$ activity level is the consistent decrease exhibited by each of the 10 compounds. The measured and predictable decrease in ${ }^{14} \mathrm{C}$ activity revealed in this study agrees well with previous research on atmospheric ${ }^{14} \mathrm{C}$ activity, the source for photosynthetic uptake of ${ }^{14} \mathrm{CO}_{2}$ by plants. Knowing the present ${ }^{14} \mathrm{C}$ activity permits one to accurately resolve additions or dilution to natural products with fossil-fuel-derived materials. Fraudulent manipulation of products to mimic those of natural origin to potentially deceive consumers can now be revealed with greater confidence.

Although not a fraudulent addition of ${ }^{14} \mathrm{C}$, the higher than predicted activities found in certain vanillin samples alerted us to a new source of vanillin production. The measured ${ }^{14} \mathrm{C}$ activities for a number of vanillin samples primarily in the years 2008 and 2009 were at least $10 \%$ higher than expected from the predicted decrease based on other compounds. Matching the ${ }^{14} \mathrm{C}$ activity with stable isotope ${ }^{13} \mathrm{C} /{ }^{12} \mathrm{C}$ and $\mathrm{D} / \mathrm{H}$ data revealed that wood lignin was a likely candidate for this new van- 


\section{R Culp \& G V R Prasad}

illin process. Because coniferous trees preserve the recent past ${ }^{14} \mathrm{C}$ activity in their growth rings, and the ${ }^{14} \mathrm{C}$ activity has decreased over the past $50 \mathrm{yr}$ since the cessation of aboveground nuclear bomb testing, any product derived from pulpwood will exhibit an averaged ${ }^{14} \mathrm{C}$ activity. Although ligninproduced vanillin has not been a major source for food-grade vanillin in the past, the technology has existed for many years. With the greater demand for vanillin in the food and flavor industry, this process has become a new and inexpensive source for vanillin production. ${ }^{14} \mathrm{C}$ and stable isotope analyses have the capability to identify this source material.

\section{ACKNOWLEDGMENTS}

The authors wish to thank the United States Flavor and Extract Manufacturer's Association for their financial and scientific support. Special thanks go to our fellow researcher scientist Alex Cherkinsky, and technical staff Larry Greenway, David Smith, and Flordaliza Smith for their support in this study.

\section{REFERENCES}

Byrne B, Wengenroth KJ, Krueger DA. 1986. Determination of adulterated natural ethyl butyrate by carbon isotopes. Journal of Agricultural and Food Chemistry 34(4):736-8

Culp RA, Noakes JE. 1990. Identification of isotopically manipulated cinnamic aldehyde and benzaldehyde. Journal of Agricultural and Food Chemistry 38(5): 1249-55.

Culp RA, Noakes JE. 1992. Determination of synthetic components in flavors by deuterium/hydrogen isotopic ratios. Journal of Agricultural and Food Chemistry 40(10):1892-7.

Culp RA, Legato JM, Otero E. 1997. Carbon isotope composition of selected flavoring compounds for the determination of natural origin by gas chromatography/isotope ratio mass spectrometry. In: Mussinan CJ, Morello MJ, editors. Flavor Analysis: Developments in Isolation and Characterization. Washington, DC: American Chemical Society. p 260-87.

Culp RA, Noakes JE. 2010. Two decades of flavor analysis: trends revealed by radiocarbon $\left({ }^{14} \mathrm{C}\right)$ and stable isotope $\left({ }^{13} \mathrm{C}\right.$ and $\left.\mathrm{D}\right)$ analysis. In: Ho CT, Mussinan CJ, Shahidi F, Contis ET, editors. Recent Advances in Food and Flavor Chemistry. Cambridge: Royal Society of Chemistry. p 9-27.

Dai K-M, Fan CY. 1986. Bomb produced ${ }^{14} \mathrm{C}$ content in tree rings grown at different latitudes. Radiocarbon 28(2A):346-9.

Dias RF, Freeman KH, Franks SG. 2002. Gas chromatography-pyrolysis-isotope ratio mass spectrometry: a new method for investigating intramolecular isotopic variation in low molecular weight organic acids. $\mathrm{Or}$ ganic Chemistry 33(2):161-8.
Doner LW, Henry 0A, Sternberg LSL, Milburn JM, DeNiro MJ, Hicks KB. 1987. Detecting sugar beet syrups in orange juice by $\mathrm{D} / \mathrm{H}$ and ${ }^{18} \mathrm{O} /{ }^{16} \mathrm{O}$ analysis of sucrose. Journal of Agricultural and Food Chemistry 35(4):610-2.

Ébongué VW, Geypens B, Berglund M, Taylor P. 2009. Headspace solid phase microextraction-GC/C-IRMS $\delta^{13} \mathrm{C}_{\mathrm{VPDB}}$ measurements of mono-aromatic hydrocarbons using EA-IRMS calibration. Isotopes in Environment and Health Studies 45(1):53-8.

Hoffman PG, Salb M. 1979. Isolation and stable isotope ratio analysis of vanillin. Journal of Agricultural and Food Chemistry 27(2):352-5.

Hoffman PG, Salb M. 1980. Radiocarbon $\left({ }^{14} \mathrm{C}\right)$ method for authenticating natural cinnamic aldehyde. Journal of the Association of Official Analytical Chemists 63(6):1181-3.

Lampman GM, Andrews J, Bratz W, Hanssen O, Kelley K, Perry D, Ridgeway A. 1977. The preparation of vanillin from eugenol and sawdust. Journal of Chemical Education 54(12):776-8.

Martin GE, Kruger HW, Burggraff JM. 1985. Radiocarbon ${ }^{14} \mathrm{C}$ differentiation of sparkling and carbonated wines. Journal of the Association of Official Analytical Chemists 68(3):440-3.

McNichol AP, Ertel JR, Eglinton TI. 2000. The radiocarbon content of individual lignin-derived phenols: technique and initial results. Radiocarbon 42(2):21927.

Nydal R, Lövseth K. 1983. Tracing bomb ${ }^{14} \mathrm{C}$ in the atmosphere 1962-1980. Journal of Geophysical Research 88(C6):3621-42. 